\title{
Jorge Asís y la ficción política del yo
}

\author{
Jorge Asís and the political fiction of the self
}

\author{
Carlos Fernández González \\ Hankuk University of Foreign Studies \\ cfernandezgonzalez@gmail.com
}

Resumen: Este artículo examina cómo Jorge Asís articula en las novelas Flores robadas en los jardines de Quilmes, Carne picada y Canguros una relación entre identidad, literatura y política en el contexto argentino del Proceso de Reorganización Nacional iniciado en 1976 y la transición democrática de 1983. La recepción crítica de dichas novelas establece una serie de tensiones entre el "campo intelectual" y el "campo político" (Pierre Bourdieu) proyectadas sobre la figura del autor y su autonomía. Utilizando la noción de "límite del canon" de Nidia Burgos, este artículo analiza cómo las instituciones literarias establecen sus operaciones a partir de escenarios ideológicos específicos. Al mismo tiempo, el doble rol de Jorge Asís como escritor y como político converge en una obra que coloca dicha tensión en su centro estético e ideológico. Finalmente, este artículo muestra el modo en que la obra de Asís confronta, desde la exclusión del canon literario argentino, los límites institucionalizados de una representación literaria de la memoria histórica, política e intelectual relacionada con el Proceso de Reorganización Nacional.

Palabras clave: Jorge Asís, Ciclo Canguros, ficción política del yo.

Abstract: This paper examines how Jorge Asís articulates in the novels Flores robadas en los jardines de Quilmes, Carne picada and Canguros a relationship between identity, literature and politics in the Argentine context of the National Reorganization Process initiated in 1976 and the democratic transition of 1983. The critical reception of these novels establishes a series of tensions between the "intellectual field" and the "political field" (Pierre Bourdieu) projected on the figure of the author and his autonomy. Using Nidia Burgos's notion of "límite del canon", this article analyzes how literary institutions establish their operations from specific ideological scenarios. At the same time, the double role of Jorge Asís as a writer and as a politician converges into a work that places this tension in its aesthetic and ideological center. Ultimately, this article shows the way in which Asís's work confronts, from the exclusion from the Argentine literary canon, the institutionalized limits of a literary representation of the historical, political and intellectual memory related to the National Reorganization Process.

Keywords: Jorge Asís, Ciclo Canguros, political fiction of the self.

Recibido: 03/02/2018

Aceptado: 03/09/2020 


\section{Introducción}

La literatura de Jorge Asís (Avellaneda, Argentina, 1946) ha trazado un recorrido sinuoso por la historia argentina reciente, del mismo modo que, como político y funcionario, Jorge Asís ha sabido encontrar a través del tiempo su espacio en zonas disímiles del arco ideológico. El vaivén estético-político general de su obra en prosa comienza en 1971, cuando pertenecía al Partido Comunista, con De cómo los comunistas se comen a los niños, un conjunto de relatos que explora las aprensiones de la burguesía porteña ante la flagrante amenaza comunista, mientras que su novela Dulces otoñales, publicada en el año 2014, repasa las andanzas de Oberdán Rocamora _alter ego del personaje Rodolfo Zalim, que es, a su vez, alter ego literario del propio Jorge Asís desde sus primeras novelas - en el París de los años noventa, cuando cumplía funciones diplomáticas al servicio del gobierno de Carlos Saúl Menem, representante de una gestión que marcó la inclusión de Argentina en el proceso global de "reforma neoliberal" descrito recientemente, entre otros, por Wolfgang Streeck.

Desde la publicación de Flores robadas en los jardines de Quilmes (1980), y con una presencia interrumpida en los medios de comunicación desde que se iniciara en el diario Clarín en 1976, donde firmó columnas reunidas más tarde bajo el título El Buenos Aires de Oberdán Rocamora (1981), la dinámica entre la figura del autor literario y la figura del político profesional no solo ha marcado el ritmo de sus temáticas, sino que ha generado, además, una tensión conflictiva en los procesos de recepción de su obra. Esto se hace evidente a partir del retrato generacional de quienes se involucraron de manera directa en las pujas políticas e institucionales que tuvieron, entre sus desenlaces, el Proceso de Reorganización Nacional, nombre del gobierno militar que ocupó el poder de facto en Argentina entre 1976 y 1983. Para analizar este conflicto estético y político pondremos el foco de nuestra atención sobre el segmento de tres novelas que daría lugar al denominado Ciclo Canguros (Flores robadas en los jardines de Quilmes, Carne picada y Canguros), en un período de producción y publicación que comienza en 1980 y concluye en 1983. Es precisamente a partir del Ciclo Canguros cuando se inaugura el conjunto recurrente de operaciones que, incentivadas o ensombrecidas por las facciones literarias e ideológicas en puja, han moldeado las condiciones para que su posición como escritor y como político se preste a ser analizada en un trabajo como este.

A partir de una nueva lectura de este conflicto, ${ }^{1}$ resultado de las relaciones, siempre complejas de desentrañar, entre las "fuerzas" del campo intelectual y del campo político, de acuerdo con las definiciones de ambos conceptos propuestas por

1 No puede obviarse que este conflicto entre literatura y política, que críticos como David Viñas y Ricardo Piglia han definido como constitutivo de la literatura argentina (a partir de "El matadero" de Esteban Echeverría), orbita sobre la obra y sobre la vida de Asís. 
Pierre Bourdieu, en este trabajo se ofrece un análisis del modo en que Jorge Asís, como sujeto literario (es decir, como autor, narrador y/o personaje) y como sujeto político, se transforma a partir del Ciclo Canguros — con el paréntesis de La calle de los caballos muertos, de 1982, novela breve que el propio autor ha definido como "insert" periférico dentro de la serie- en objeto crítico multiforme balizado por diversas tensiones. Sobre la constatación de este proceso de construcción de una identidad, desde los planteamientos teóricos que se desarrollan a continuación, la pregunta doble en torno a la cual se articula este análisis es la siguiente: ¿cómo se restituye en la ficción aquello que pertenece a la praxis política, y de qué manera la praxis política reclama para sí aquello que el escritor aspira a conservar como centro estético de su obra?

\section{Los límites del canon: literatura argentina y proceso militar}

Para ubicar a Jorge Asís en los límites del canon de la literatura argentina es necesario, en primer lugar, establecer cómo este se delimita en el periodo de nuestro interés. Considerando que el canon literario está constituido por una selección de los textos que condensan una tradición cultural, y que son las tendencias académicas las que sistematizan y dan forma al debate sobre dicha tradición, Nidia Burgos establece el punto de partida en el marco específico de la literatura de Jorge Asís. Es evidente que "las exigencias de la enseñanza tienden a modificar el canon antes que a conservarlo", y que solo a partir de ese movimiento permanente la bibliografía académica se renueva en una interacción que puede ser mayor o menor en función de las modas, las tendencias y los consumos de las instituciones que la rodean, así como de las fluctuaciones del mercado editorial (un mercado editorial que, desde 1980, con todas las consecuencias que conlleva la etiqueta, cataloga a Jorge Asís como best seller). Sin embargo, Burgos señala también algo menos percibido: que la redefinición y la reestructuración del canon se atiene muy frecuentemente al modo en que la escritura del presente transforma y modifica la lectura del pasado y de la tradición (187). Como desvela la etimología, la palabra griega kanon, con su significado de 'regla' o 'precepto', delimita en su acepción más reconocida el conjunto de libros tenidos por la Iglesia católica como auténticamente sagrados. A partir de esta denominación, el carácter sacro del recorte inaugura una extensa polémica que, en el contexto de este trabajo, conviene no dejar de tener en cuenta: ¿quiénes, al amparo de instituciones, reputaciones y dominios sociales diversos, se apropian del poder de establecer qué sí ha de leerse y estudiarse y qué no y, sobre todo, con qué objetivos establecen el sentido de esa cualidad arbitraria?

En relación con lo que Burgos define, a la luz de los vaivenes de la ideología dominante en las instituciones académicas, desde el retorno de la democracia en 1983, como el carácter literario de un "peligroso imprevisible" (202), es necesario establecer que la literatura de Jorge Asís enfrenta un conflicto entre lo que se per- 
cibe como la ideología del autor y lo que se percibe como la ideología del texto. A partir de ese equívoco inaugural, la literatura de Asís ha sido cuestionada - primero, durante el Proceso, bajo acusaciones de colaboracionismo, y después, durante el menemismo, bajo acusaciones de complicidad — por buena parte de los catedráticos y los intelectuales organizados alrededor de la institución académico-literaria argentina. Esta discusión alrededor de la ideología del autor y la ideología del texto vivió, como es conocido, uno de sus momentos de mayor trascendencia en el Primer Congreso de Escritores Soviéticos de 1934, donde el problema fue colocado en el centro de la discusión estética y política de la época, referencia cuya distancia con el clima cultural del período histórico argentino que nos interesa se acorta si consideramos que Asís no solo fue miembro del Partido Comunista hasta 1973, sino que, además, su interés en las normas exigidas por la burocracia comunista lo llevó a visitar la Unión Soviética, así como a la escritura y publicación de una de sus obras clave: Del Flore a Montparnasse: el sentido de la vida en el socialismo (2000).

Desde entonces diversos críticos, en la estela de la crítica neomarxista, han analizado detalladamente el problema entre obra e ideología. En líneas generales se establece que, si bien aquel paralelismo inmediato propuesto por los críticos y teóricos de los años treinta fue uno de los "más devastadores ataques a la cultura artística de la historia moderna" (Eagleton 121), una de las consecuencias contemporáneas de ese intento de fusionar la obra con el autor - $-\mathrm{y}$ de juzgar una obra no como elemento autónomo, sino como "reflejo" del compromiso ideológico del autor con una causa - pervive aún en el problema señalado por Fredric Jameson, a propósito de las repercusiones de los Estudios Culturales. A partir del análisis de su influencia en el pensamiento académico actual, Jameson formula sus reparos frente al modo en que, desde su auge en la década de los noventa del siglo pasado, los llamados Estudios Culturales lograron establecerse "como una suerte de guía del modo en que la gente se ve a sí misma, como agentes activos, cuyo sentido del yo se proyecta y se expresa en un creciente espectro de prácticas culturales" (34).

Como punto de partida diremos que, lejos de neutralizarse a través de los devenires de la historia reciente de las ideas, la relación conflictiva y muchas veces ambigua entre las motivaciones políticas del pensamiento crítico en las instituciones académicas argentinas, en especial tras su restitución como tal con el regreso de la democracia, y la reapertura de una vida intelectual libre en las universidades (junto a la consecuente cristalización de dicha libertad en los criterios políticos y estéticos que incluyen y excluyen del canon literario), llega con la obra de Asís a un momento de máxima tensión. Este problema, por otro lado, expande y complementa, desde la dimensión del enfoque institucional, los problemas etnográficos y sociológicos vinculados a la construcción de la figura de autor de Jorge Asís, de acuerdo con la tesis de Marcus Sylvan Palmer, a partir de la exploración de la propia identidad y 
de las transformaciones de un escritor que es, además, descendiente de inmigrantes árabes (41). En este sentido, resultan iluminadoras las delimitaciones realizadas por Burgos sobre el modo en que se constituye un corpus prestigioso y consensuado por un campo intelectual (es decir, un canon) y el eco de los reparos señalados por Jameson sobre la influencia de las modas académicas — también políticas-en las instituciones universitarias. En nuestro estudio, contribuyen a la comprensión de los modos en que las instituciones de la literatura argentina organizaron y jerarquizaron, bajo una coyuntura política con motivaciones específicas, un corpus del que Jorge Asís resultó excluido.

Un primer análisis de las novelas que nos interesan aquí —y, en particular, de Flores robadas en los jardines de Quilmes- ubica a Beatriz Sarlo entre las voces más relevantes del período, al poner en escena uno de los conflictos más relevantes alrededor del autor. La de Sarlo fue una de las primeras voces académicas en señalar un tema clave en la recepción crítica de la literatura de Asís: el "pacto de mímesis con los valores, las experiencias, los mitos, los discursos, el nivel de lengua, de un amplio sector del público" ("Política, ideología y figuración literaria" 50). A partir de aquel momento, la sospecha de una suerte de pacto ideológico, entre el modo en que la obra narrativa del Ciclo Canguros retrata la generación de los desaparecidos durante los años del Proceso y la ubicación de Jorge Asís ante dicha coyuntura histórica, se combina con la noción problemática de ese "amplio sector del público" que apoyó — bien desde la complicidad, bien desde el silencio— al gobierno de facto de aquellos años y que, por lo tanto, de acuerdo con el análisis de Sarlo, encontraría en la novelística de Asís un tipo de literatura ideológicamente compatible con su propia mirada de la época. Un proceso vasto y de numerosos ejemplos universales que Slavoj Žižek, considerando el modo en que los objetos de la industria cultural nunca son ajenos a la sociedad en la que circulan, ilustra bajo una perspectiva más amplia de análisis ideológico: "un estado que depende de una conjunción histórica concreta se presenta como un rasgo eterno y universal de la condición humana; el interés de una clase en particular se disfraza de interés humano universal" (81).

En ese contexto, la crítica de Beatriz Sarlo resulta imprescindible para una puesta en cuestión de la recepción de las novelas de Jorge Asís, tal como han quedado delimitadas por ella en el marco de las discusiones estéticas y políticas inmediatamente posteriores al Proceso. De acuerdo con su interpretación del problema, la literatura explaya su contenido de verdad bajo la forma de la figuración, porque "no reconstruye una totalidad a partir de los disiecta membra de la sociedad", sino que propone "cursos de explicación y constelaciones de sentido que plantean lecturas diferentes y alternativas del orden de lo real, según una pluralidad de regímenes discursivos y de estrategias de ciframiento" ("Política, ideología y figuración literaria" 46). Consideramos que, más allá de tratarse de dos definiciones realizadas 
por la misma crítica y, sin embargo, en apariencia opuestas en lo que respecta a su interpretación del funcionamiento de la literatura, lo que verdaderamente explica la divergencia es la literatura misma de Asís, esto es, su influencia directa en la perspectiva crítica bajo la cual su obra es analizada.

\section{Ciclo Canguros}

La pregunta sobre la recepción de la literatura de Jorge Asís requiere una indagación en las operaciones que esa literatura propone y desarrolla sobre las coordenadas políticas y sociales de su época, con el objetivo de poder clarificar en qué términos se llevaron adelante las incomodidades suscitadas por sus novelas y cómo estas influyeron en la figura del autor y en su figura pública. El Ciclo Canguros se inicia en 1980 con Flores robadas en los jardines de Quilmes, novela que alcanzó tal éxito comercial que propició la aparición de catorce ediciones sucesivas con más de 180.000 ejemplares vendidos, a lo que se sumó la película dirigida en 1985 por Antonio Ottone y el desembarco de Asís en el mercado editorial español. A partir de los debates suscitados desde 1983, la figura del "militante pícaro", según la denominación de Casas de Faunce, pasaría a confrontarse con la acusación de "best-seller de la dictadura", sobre la que reflexionan Abdelhamid Amarouch y Andrés Avellaneda. En los términos de esa acusación se perfila la complejidad de la autonomía como autor de Jorge Asís, envuelta desde el principio en asuntos ajenos a la valoración literaria, condición de tal relevancia que obliga a recordar no solo que Flores robadas... está dedicada a un desaparecido, sino también que la novela Don Abdel Zalim: el burlador de Domínico, publicada en 1972, fue censurada entonces por los decretos presidenciales dictados por el Teniente General Jorge Rafael Videla (entre marzo de 1976 y marzo de 1981) y referidos a la prohibición de libros, mientras que la novela Los reventados, de 1974, fue galardonada con una Mención del Premio Casa de las Américas en la Cuba de Fidel Castro.

Por otra parte, en un registro que combina la narración de las aventuras suburbanas del joven Rodolfo Zalim con la manifestación de opiniones sin temor a la mirada cínica sobre el panorama social y cultural del momento, la voz profética del antiguo militante del Partido Comunista aparece entremezclada con la voz apocalíptica del testigo de los crímenes del Proceso y marca, así, el deterioro en la voluntad de la generación de la que Zalim —y/o Asís_ - forma parte. El clima de confusión que parece cernirse sobre todos ellos se pone en evidencia cuando, ante la angustia de Samantha, con quien había tenido una relación, Rodolfo, en un tono deliberadamente cínico, le dice lo siguiente:

estás empachada, comprate un televisor y te vas a curar, mirá las sonrisas de Percivale, los almuerzos de Mirtha Legrand, las propagandas. Y vas a comprender que, después de todo, la vida tiene sentido. A lo mejor, el secreto de 
la felicidad puede ser ese, y la ubicación, ese don preciado, puede señalarlo el televisor. Hay que seguir la corriente, para pasarla bien, sin pensar. Y comprar todo lo que nos sugiere, leer Gente, y tratar de hacer dinero, mucho, para comprar todo y ser fuertes, cambiar un coche por año y tener muchos, muchos hijos. Cualquier cosa, si pueden, que arreglen el mundo ellos. (Asís, Flores robadas 195)

A partir del éxito singular y simultáneo a la publicación de la novela que Asís tuvo como columnista en Clarín, interesa destacar hasta qué punto, a pesar de la presunta ambigüedad de pasajes como el citado, lo que la obra de Asís propone a lo largo del Ciclo Canguros es, antes que un acto de sumisión, un acto de disidencia frente a las limitaciones culturales impuestas por el gobierno militar. Podemos afirmar, por lo tanto, no solo que la denominación de "best-seller de la dictadura" resulta a priori discordante con un libro cuya dedicatoria reza "a Haroldo Conti ¿in memoriam?”, 2 sino también que, como pieza inaugural del Ciclo Canguros, Flores robadas... opera en un registro de introspección y retrospección que, sin eludir el clima represivo del Proceso, antecede al que, como veremos, se convierte en un registro de denuncia en Carne picada y, en Canguros, en una entusiasta reflexión acerca del inminente porvenir de Argentina en democracia. El narrador lo deja claro al inicio de Flores robadas..., donde, cuando todos se han retirado a sus habitaciones, describe así el acto de escribir en la casa familiar:

desenchufarme del periodismo, de la familia, de la literatura, y pensar más allá de las noventa líneas, de mi viejo combate diario, necesito comprenderme, quizá releerme, y preguntarme, a fondo, qué es lo que quiero hacer con mi vida. Si sirve seguir intentando, por ejemplo, una obra, y qué sentido tiene seguir amargándome por esa culpa que me espera, en el cajón del escritorio. Tres carpetas abultadas, la novela de un joven promisorio, de un joven jodido, al que la realidad, con su topadora, le pasó por encima. (Asís, Flores robadas 12)

Y poco después, en alusión al silencio de quienes ya no pueden o no se atreven a seguir escribiendo, sentencia: "puedo pensar, porque todos duermen" (14). A partir de aquí, la narración comienza también a desplegarse bajo los parámetros de la denominada autoficción, en virtud de la cual el escritor se inventa una personalidad y una existencia conservando, no obstante, su identidad real e incluso su verdadero nombre (Colonna 1989, 30). Entre las categorías de la autoficción, Pozuelo Yvancos destaca tres: la referencial o biográfica, a la que considera próxima a la autobiogra-

2 Haroldo Conti (Argentina, 1925-1976) fue un escritor secuestrado el 4 de mayo de 1976 por el Batallón 601 de Inteligencia del Ejército. Sus restos nunca fueron hallados y forma parte de la nómina de desaparecidos del Proceso. 
fía; la reflexivo-especular, en la que se incluye la metaficción; y la figurativa, que es la modalidad adoptada en la novela de Asís, en la cual "hay una transfiguración del autor en un personaje que, tomando rasgos de él, puede resultar inventado" (21). Esta forma de la autoficción implica una constante construcción y deconstrucción de la identidad, un ir y venir y un dejarse ver entre los espacios referenciales y los espacios ficcionales, en un procedimiento de desafirmación del sujeto, descentrado y fisurado en su figuración, que se corresponde con la afirmación del sujeto en un devenir irregular, rizomático, inquietante y, desde cierta perspectiva, absolutamente intolerable.

Pues bien, si el problema de la figuración del yo se resuelve principalmente en la relación entre el texto y la vida, la conjunción deliberada en Flores robadas... entre lo uno y lo otro, atravesada, a su vez, por el período de transición entre los últimos años de un gobierno de facto y los primeros de un gobierno democrático, ilumina la delicada situación de los límites literarios y políticos entre Rodolfo Zalim y Jorge Asís. En este trabajo, con independencia de la variante de la autoficción a la que pertenece cada obra, es importante señalar que la permeabilidad que todas ellas presentan en común entre el texto y la vida ha funcionado, en cuanto forma literaria predominante en las novelas y en el contexto social de las que surgieron, como principal obstáculo epistemológico para la recepción crítica de la obra del autor (e incluso como principal obstáculo en la carrera del político). La reflexión en torno al género autobiográfico, por lo tanto, resulta útil en este caso en virtud de sus aportaciones a lo que Francisco Rodríguez Cascante describe como la elaboración de un yo, "que es el reemplazo construido por la memoria de aquel que en realidad vivió los hechos que se recuerdan” (15). ¿Cuánto de la ilusión con la que el Ciclo Canguros da sentido al más terrible acontecimiento político de su generación, en el preciso momento en que otros escritores permanecían exiliados, muertos o en silencio, plantea una discusión política antes que literaria? En este punto, el estilo satírico de la obra y el efecto de distanciamiento que establece frente al objeto narrado corrobora la hipótesis de Paul de Man sobre la ambigüedad de "esos dos lenguajes, el de la agresión o el del reposo" (117) que, en los Essays upon Epitaphs de Wordsworth, establece un aparente valor equidistante sobre el narrador que sirve para prorrogar, asimismo, la necesidad de una definición precisa de sus motivaciones y de su identidad; es decir, ese núcleo inaccesible — y de tensiones inmanentes- o "prosopopeya del nombre y de la voz" (118) que desata la privación y la desfiguración (de-facement) de aquello mismo que la autobiografía (o la autoficción) pretende restaurar.

No es autobiografía, declara irónicamente Zalim: "No, amigos, así no va. Pienso que debo alejarme, asumir mi ambigua condición de narrador omnisciente e impedir que los incautos supongan que estoy redactando una autobiografía. Mejor, 
en todo caso, es ponerme a juguetear, por retomar la recursiva tercera persona, así yo mismo trato, con el lenguaje, de embaucarme y de creer que estoy hablando de otro, de cualquiera de mis tantos personajes de ficción” (19). Así, a lo largo de la novela no solo se mezcla la narración en primera persona con la narración en tercera sino que, en su intento de hacer inteligible el trauma político y social del pasado reciente, establece también, con Samantha - personaje caracterizado por una mirada ingenua sobre la realidad-, un distanciamiento que incluye una crítica mordaz a ciertos elementos del lenguaje coloquial de su generación, "ese vocabulario de porquería, exprimido, de burgués que quiere desatarse" (45), relacionado con los ambientes académico-militantes en los que se habían formado y de los que habían surgido muchos de los referentes políticos y sociales perseguidos por el Proceso. Para Zalim, durante el gobierno anticonstitucional este es el vocabulario de la derrota y delimita un campo semántico en el que "vivir intensamente" se combina con "la venta" de otros conceptos que el presente desnudaría, a través de "los militares" (165), como farsas inviables: la angustia, la depresión, la realización, la liberación o la revolución. Como concluye Maristany, esta evaluación negativa del discurso militante tiene como objetivo "demostrar precisamente que la militancia no es más que un 'discurso' y que, como tal, forma parte de lo irreal y lo ilusorio" (144).

Carne picada, publicada en 1981, presenta un tono más nostálgico que su predecesora. Al construirse alrededor de Luciano, un personaje recién liberado de la cárcel de Villa Devoto, tematiza la vida durante el Proceso centrándose no solo en las víctimas morales, sino también en las víctimas directas de la represión armada y en los victimarios — como el representado por Matías - que la hacen efectiva de manera clandestina. ${ }^{3}$ Por esta razón el registro satírico y ligeramente picaresco de Rodolfo Zalim, "un escritor desconcertante que se situaba en el contorno impreciso de la izquierda pero que era, admitámoslo, ya desfachatadamente escéptico" (212), en comparación con el modo en que se presenta en la primera parte del Ciclo Canguros, resulta aquí apaciguado por el tono directo de la represión del Estado bajo un plan que, según Matías, se cumple bajo "la consigna de exterminar" (270) y que roza incluso al propio Zalim:

sentí, desde el portero eléctrico, la voz de Matías, sobre todo la palabra Matías, y creí, absurdamente, que podía haberme llegado el final. O por lo menos Rodolfo sintió que debía enfrentarse a una dramática situación límite, porque alguna vez a Matías lo tendría que encontrar. Para colmo no estaba solo en el bulín. Aparte de Silvia, que sabía que Rodolfo tenía un amigo que se había

3 Carne picada es la primera novela de Jorge Asís publicada en España y repite, en su epígrafe inicial, otra alusión a las víctimas de la dictadura: "a Lucina Álvarez, a Óscar Barros, al hijo que deben criar los abuelos". 
hecho botón, estaba una piba insistente del pe ese te, el partido socialista de los trabajadores. . . Se llamaba Nora y creo que no la mataron. (Asís, Carne picada 211)

En contraste con el carácter de la relación entre Zalim y Samantha en Flores robadas..., la violencia a lo largo de este segundo segmento del Ciclo Canguros desplaza casi todo componente erótico de la narración. Este "más allá de la erótica", de acuerdo con la definición de Peter Sloterdijk, representa, mediante la inmersión accidental de Zalim en la sociabilidad cotidiana de los asesinos al servicio del Proceso, no solo "aquel odio que constituye el reverso del amor" (24-25), sino también una parte singular de ese proceso más amplio - y no menor en el Ciclo Canguros - sobre el cual Sloterdijk ubica la necesidad de una formación, también política, del orgullo y la auto-afirmación del hombre. Estas dos disciplinas, sustentadas en las "energías thimóticas" (16) de la ira y la violencia como fuentes para el desarrollo de un "sentimiento de dignidad" (22), contrastan de manera abrupta con el retrato que Asís hace del voluntarismo romántico —un deseo de "principios erotodinámicos" - imperante en la atmósfera de los militantes y los simpatizantes políticos vinculados a los diversos movimientos de centro e izquierda activos en Argentina hasta la irrupción del Proceso, que habían colocado buena parte de sus expectativas en la posibilidad de una revolución. La violencia de Carne picada, por lo tanto, puede ser leída en términos psicopolíticos y, más allá de la mera reconstrucción realista de las circunstancias históricas, como la contracara del erotismo. Aun mostrando "caminos a los objetos que nos faltan y a través de los cuales nos sentimos complementados" (26), el erotismo resulta ensombrecido en la novela por la thimótica que abre a los hombres caminos a través de los cuales son capaces de afirmar lo que tienen, pueden, son y quieren ser; algo de lo que los miembros politizados de su generación resultan incapaces, debido, según Zalim, precisamente a la irrupción violenta del Estado.

En una ciudad de Buenos Aires surcada por los grupos de tareas que exhiben sus armas con impunidad, ${ }^{4}$ la ambigua ideología de Rodolfo Zalim no duda en describirse como "políticamente huérfana", sin dejar por ello de confrontarse, como escritor, con los dilemas del acotado campo intelectual del momento. En especial cuando, al sopesar su antiguo paso por el Partido Comunista, y considerándose preso de un escepticismo incontrolable, Zalim se pregunta sobre el sentido de un deber intelectual que lo obligaría, en calidad de superviviente, a un "optimismo" y a una "esperanza" que no encuentra viables: "de esa mercadería entusiasta no

4 Una de las denominaciones, junto a la de "GT", asignadas a los grupos armados que operaban durante el Proceso sin identificación visible y al servicio de las diversas fuerzas militares, cumpliendo tareas de inteligencia y llevando a cabo detenciones, secuestros y asesinatos. 
tengo, vayan a comprársela a otro escritor, yo vendo mierda, lo que tenemos y lo que definitivamente somos" (Asís, Carne picada 231-32).

Anticipándose a las dificultades planteadas por una obra literaria "tan marcadamente autobiográfica para la gilada" que cualquier "delirante libro suyo podía servir para sentenciarlo", la discusión de Zalim acerca del rol del escritor bajo el Proceso se transforma en una toma de posición estética y política en la medida en que, como muchos otros intelectuales, se reconoce parte de aquellos catalogados como escritores de la subversión marxista, integrantes de una lista que "temerosamente la paseaban por editoriales y librerías", y de la que Zalim "era el último porque los seres de sal la habían confeccionado por burocrático orden alfabético, los tres últimos escrachados eran Francisco Urondo, Rodolfo Walsh ${ }^{5}$ y Rodolfo Zalim" (Asís, Carne picada 234).

Lo que llamamos toma de decisión política encuentra una particular resonancia crítica en los años inmediatamente cercanos al golpe de Estado de 1976 y también en la reconstrucción democrática a partir de 1983. Situando en el foco de la discusión esa "exaltación sacralizada de las vidas heroicas inmoladas y el modo en que esa memoria obtura y evade las voces urgentes de los vivos" (Mavrakis), el registro histórico de Carne picada encuentra parte de su sentido. ¿Dónde? En lo que Sloterdijk denominó, en su extenso análisis sobre la ira, "esperanza de los apocalípticos", esto es, la suposición materialmente histórica de que "más pronto o más tarde, tendrán que experimentar el ocaso de este mundo, pero en cualquier caso durante su vida. . . De esta predisposición deriva el pensamiento diagnosticador del final de los tiempos que va transformando las cosas en señales, y las señales en indicios: la matriz de todas las teorías críticas" (116-17).

Revelado como esperanza o arquetipo religioso, cuyo origen se remonta en el mundo antiguo a la apocalíptica de los Seléucidas y al enfrentamiento opresivo experimentado por los pueblos del Oriente Medio bajo dominio del Imperio Romano, este marco de análisis psicopolítico del "resentimiento" ofrece un tamiz adecuado para una lectura de este segmento particular del Ciclo Canguros, como ejemplo moderno del tipo de sentimiento vital del apocalíptico dominado por la expectativa próxima de un colapso (social, político y cultural) de lo existente que, en todo caso, perdonará a quienes experimenten dicho sentimiento. En este sentido, la novela con la que concluye el ciclo reubica a Zalim, no como observador crítico de

5 Rodolfo Walsh (1927-1977) y Francisco "Paco" Urondo (1930-1976) fueros escritores argentinos y activistas políticos asesinados durante la dictadura militar. Sus nombres y sus obras serían fuertemente reivindicados desde 1983 a partir de un posicionamiento en el campo intelectual trazado sobre procesos que, desde la "hagiografía" estimulada por el arco ideológico de izquierdas, encontraría un alto valor simbólico dentro del campo político. En este sentido, las operaciones literarias y su entrecruzamiento con la política establecen una relación especular ante el caso Asís. 
los desastres propiciados por el gobierno militar, sino como actor crítico entre los muchos involucrados en la reconciliación propuesta por la democracia. ${ }^{6}$

A diferencia del Rodolfo Zalim de Flores robadas..., el Zalim de Canguros, publicada en 1983, reelabora su tono con un registro menos atropellado y más profundo. Entre otras variaciones, replantea sus referencias culturales dejando atrás aquellas que subrayaban la pertenencia popular como bonaerense de Quilmes para emparentarse ahora, mediante comparaciones —irónicas, pero no ingenuas-, con figuras cosmopolitas como la del actor Omar Sharif. Las postales de la pobreza, tal como se retratan en espacios suburbanos como San Francisco Solano y en el color latinoamericanista de su feria, no ofrecen más sustento narrativo que el de una reconstrucción autobiográfica empleada por el propio narrador para destacar, ante la llegada de la democracia, una capacidad de improvisación y adaptación ya probada contra toda posible catástrofe. Este es el ánimo con el que se muestra (a) Zalim: "si no se desmantelaba el aparato represivo, se marchaba, nuevamente, a otro enfrentamiento, a una guerra civi. . . Con la Argentina harían otro Líbano, pero no tenía sentido discutir, el alfonsinista tenía confianza, decía atinadamente que la salida sería difícil pero se iba a encontrar" (Asís, Canguros 238).

No obstante, al mismo tiempo que la expectativa política ante el nuevo gobierno de Raúl Alfonsín no excluye una interrogación acerca de la capacidad del partido radical para gestionar los conflictos que se avizoran — panorama que la historia argentina presenciaría cuando Alfonsín puso fin a su gobierno y cedió el cargo al electo Carlos Saúl Menem-, como escritor, tal como se presenta a sí mismo en el Ciclo Canguros desde el inicio, Zalim tampoco esquiva los conflictos de su posición en el campo intelectual. Desde allí, en una suerte de mea culpa, invoca el peso de la experiencia política reciente y el trauma que esa experiencia imprimió en la representación estética de su vida, de su época y de su propia figura a través de su obra:

durante demasiados años viví hablando tonterías para sobrevivir, me exhibí como nadie, anduve con un espejo a cuestas por toda la ciudad y vi cómo la gente al ver su verdadero rostro se espantaba. Intenté, eso fue lo peor, hacer un culto de mí, demasiado tarde o apenas ayer comprendí que era apenas un

6 El gobierno de la Unión Cívica Radical dirigido por Raúl Ricardo Alfonsín (1927-2009) atravesaría diversas crisis políticas y económicas entre 1983 y 1989, cobrando especial relevancia aquellas que derivaron en enfrentamientos institucionales con los sectores castrenses. Opuesta al peronismo, la UCR alcanzaría el poder recurriendo a organizaciones de dirección como la Junta Coordinadora Nacional y Franja Morada. Ya como gobierno instituido, la UCR marcaría a través de sus referentes intelectuales y su intervención directa en la autonomía del campo intelectual los "pases de facturas", en palabras del propio Asís, que lo mantendrían alejado del mapa de la cultura argentina, como relata en Cuaderno del acostado (1988). 
humano vulgar, un canguro como digo yo, un omnipotente que lucha para que no se descubra su impotencia. (Asís, Canguros 258)

\section{Jorge Asís y la invención de la identidad}

El Ciclo Canguros problematiza cuestiones literarias al abrir una discusión acerca de la representación cultural, histórica, narrativa y autobiográfica del autor/narrador/personaje en el contexto de la dictadura militar, y problematiza cuestiones políticas al colocar la autonomía de dicho dispositivo narrativo en tensión con las enunciaciones del "ideosema dominante" en el campo político (Ávila Martín y Linares Alés), signado primero por el Proceso, con las críticas de Zalim al gobierno militar, y después por la democracia, con las críticas al gobierno alfonsinista. La exclusión de Jorge Asís del canon literario argentino fue abordada con detalle en el trabajo ya mencionado de Nidia Burgos, ${ }^{7}$ y en este trabajo, que parte de la confirmación de aquella exclusión, se pretende delimitar el problema de la identidad literaria y política de Asís. En este sentido, si bien el debate entre modernidad y posmodernidad excede las preocupaciones aquí planteadas, conviene destacar, con Franco Rella, la "posibilidad de re-experimentar las cosas que están a nuestro lado" (255) en el contexto de una discusión ocupada en precisar algunas de las dificultades de la fragmentación de la experiencia, así como su restitución a través de un frágil habitar poéticamente. De ahí que la invención, la mutación y la caducidad se conviertan en elementos recurrentes en la identidad literaria de Asís, sin excluir lo que Vicente Raga Rosaleny describe, a propósito de los efectos del estilo, como "ironía creadora de una comunidad de lectores" (495), marcada por la posibilidad de recrear aquello narrado y, al mismo tiempo, corregirlo, corriendo el singular peligro de hundirse en una ironía tal que el autor acabe por ser igual que "un perro mordedor que, aparte de morder, ha aprendido también a reír" (497).

Como se ha señalado, no han faltado ocasiones en las que la crítica literaria simplificó tales problemas con el "castigo" de una marginalización que elude preguntas nada extrañas a la literatura argentina desde que David Viñas, a propósito de los viajes a Europa de Sarmiento, señalara ese trabajo balzaciano interesado en desgarrar la zona de lo vedado y reconquistarse a través de una versión de su objeto "que no se corresponda con las visiones elaboradas" (31). Sin embargo, es en la grieta identitaria colectiva entre la experiencia militar inaugurada en 1976 y la ex-

\footnotetext{
7 La discusión iniciada en 1983 alrededor de Jorge Asís y "los límites del canon" incluye no solo los trabajos realizados por críticos canónicos como Beatriz Sarlo, sino también eventos como el organizado por Saúl Sosnowski en la Universidad de Maryland en diciembre de 1984, junto a intelectuales como Jorge Lafforgue. Desde entonces, académicos y críticos como David Viñas, Roland Spiller, Andrés Avellaneda y Horacio González, entre otros, han dedicado atención al "problema Asís". La revista El ojo mocho, por ejemplo, le dedicó su número 16 (2001-2002).
} 
periencia democrática inaugurada en 1983 donde la identidad de Jorge Asís —en el doble papel del alter ego con el cual narra sus novelas, Rodolfo Zalim, pero también como autor dentro del campo intelectual - parece conjurar, a través del Ciclo Canguros, las incomodidades del rol vicario que, de acuerdo con Beatriz Sarlo, produce cualquier "reconstrucción memorialística de la memoria" (Tiempo pasado 129). Es evidente que la representación del Proceso en la obra de Asís resulta profundamente imbricada, a causa de su éxito comercial y su impacto polémico en la crítica, con la figura autoral de Asís y con su posterior participación directa en la política argentina. En este sentido, el Ciclo Canguros se convierte en un singular ejemplo literario-político de posmemoria, o de "memoria de la memoria", según la reelaboración en segundo grado que, respecto a Jorge Asís, Rodolfo Zalim hace de la época de la militancia política y de las expectativas y los fracasos de toda una generación. En consecuencia, las tres novelas que lo componen no tardan en presentarse ante los críticos (y ante los políticos involucrados en la historia del Proceso, sin que esto atribuya participaciones activas u omisiones pasivas de ningún tipo) como piezas literarias extremadamente sensibles, por su capacidad para narrar y otorgar un sentido ambiguo a lo que, como explica Sarlo, representa un pasado no vivido pero muy próximo - y donde se combinan, además, los intereses múltiples de desaparecidos, exiliados y supervivientes_- que llega al presente democrático (130).

Es en este cruce de mediaciones literarias y también políticas, ubicadas sobre las cicatrices mismas de la última dictadura militar y su representación narrativa, donde la identidad literaria y política de Jorge Asís ${ }^{8}$ reabre - y no clausura - aquellas preguntas clásicas de Paul Ricoeur: qué presente se narra, en qué presente se recuerda y cuál es el pasado que se recupera. Y estas cuestiones constituyen, a la sombra de la violencia del periodo, lo que Žižek denominó “el núcleo traumático no simbolizable” (122), la herida simbólica aún no resuelta ni en el canon literario argentino ni en el campo político. ${ }^{9}$ Entre las consecuencias directas de este trauma y de las dificultades epistemológicas que supone para un segmento de la crítica canónica, para el mercado editorial e incluso para determinadas facciones de la política argentina, la identidad de Jorge Asís ha transcurrido desde entonces en el

8 El catedrático argentino Daniel Link, especializado en la obra de Rodolfo Walsh, traza un recorrido por los años setenta en el que omite toda mención a Asís. Es notable cómo la figura de Asís como retratista del Proceso es reemplazada entre los críticos (aunque no entre los lectores) por la de Ricardo Piglia, cuya Respiración artificial, publicada el mismo año que Flores robadas..., es leída por varios críticos como el texto clave de aquel período. No es el caso de Luis Gregorich, quien rechaza la "estéril oposición" que enfrentó a las novelas de Asís con la novela de Piglia. Para él, Respiración artificial "en realidad complementa y no enfrenta a libros como Flores robadas en la multiforme producción literaria nacional" (117). 9 Las discusiones sobre la cifra definitiva de víctimas del Proceso continúa siendo motivo de debates y polémicas entre distintos partidos políticos, familiares de víctimas y funcionarios gubernamentales desde 1983. 
marco de una aparente indiferenciación — pública— entre el artista y el político10, en paradójica semejanza con el proceso de "des-profesionalización del arte" que ha descrito Boris Groys:

el público democrático quiere encontrar en el arte las representaciones de asuntos, temas, controversias políticas y aspiraciones sociales que activan su vida cotidiana. Con frecuencia, se considera a la politización del arte como un antídoto contra la actitud puramente estética que supuestamente le pide al arte que sea simplemente bello. Pero, de hecho, esta politización del arte puede ser fácilmente combinada con su estetización, en la medida en que se las considere desde la perspectiva del espectador, del consumidor. (11)

\section{Conclusiones}

Atravesada por discusiones institucionales de orden académico y político que aún intentan delimitar y establecer un sentido consensuado - y reparador- sobre la memoria histórica vinculada al significado del Proceso de Reorganización Nacional, así como también sobre las representaciones estéticas que dicho episodio ha puesto en marcha desde la restitución del orden democrático, la identidad literaria de Jorge Asís, al igual que su posición y valoración dentro del campo intelectual argentino, cumple el rol que Gilles Deleuze asigna al "símbolo rotativo", aquel que, sin principio ni fin, siempre está en el medio de las cosas, entre las cosas, tensionando - y amenazando con sustituir— "el poder de decisión por el poder de juicio" (72).

En ese sentido, el trabajo auto(ficto)biográfico de Jorge Asís en su literatura insiste desde el primer momento en hacer del continuo entre la experiencia vital y la imaginación literaria el centro mismo de su obra. Las tensiones alrededor de su identidad literaria, por lo tanto, no pueden ser estéticas sin ser también políticas, en una tradición que se remonta a los orígenes mismos de la literatura argentina y que el Ciclo Canguros reinaugura sobre la última dictadura militar, uno de los episodios clave del siglo XX argentino. Dicha invención literaria de una identidad no puede, por lo tanto, escapar ni mantenerse ajena a los ecos de una discusión aún en marcha sobre los efectos que el trauma del Proceso generó sobre las subjetividades políticas involucradas. Lo hizo, primero, con la terrible derrota de la expectativa revolucionaria encarnada en los segmentos más politizados de la generación de los

10 Desde la compilación de artículos periodísticos publicados bajo el título La ficción politica (1985) hasta El kirchnerismo póstumo (2011), el propio autor ha llevado a cabo un proceso singular de "estetización de la política" o de "politización de la estética", y es interesante señalar que, más allá de la recepción crítica de su obra, Asís mantiene su propio "obstinado silencio opaco" frente a los especialistas que "pretenden identificarlo", parafraseando el análisis realizado por Hito Steyerl en Los condenados de la pantalla. 
años setenta, en la cual se incluye el propio Asís; y lo hizo de nuevo, después, con la reelaboración de esa expectativa y de su derrota a la luz de la recomposición institucional democrática de 1983, inaugurando a partir de ese momento una réplica institucional. Esta respuesta, por un lado, desplazaría en su vertiente literaria a la obra de Asís hacia "los límites del canon", marginando su posición en el campo intelectual, mientras que, por otro lado, facilitaría desde la vertiente política el camino formal hacia la función pública. Preguntarnos, ante un caso como el descrito, si Asís es un escritor que hace política o un político que hace literatura desvela el tipo de equívoco al que se donan — bajo los intereses literarios y políticos esbozadoslas instituciones literarias y políticas ante las que la propia obra de Asís mantiene una consciente distancia. Esta distancia, muy bien calculada, le permite expresar una singular libertad creativa con éxito en el mercado editorial y, al mismo tiempo, ejercer una crítica que no excluye la denuncia contra el funcionamiento del propio campo intelectual.

Testigo privilegiado de los eventos históricos ocurridos entre 1976 y 1983, aquello que Rodolfo Zalim/Jorge Asís relata a lo largo del Ciclo Canguros insiste en no ceder al pacto tácito de las conveniencias intelectuales o políticas, aun cuando el precio de dichas transgresiones ha atentado no solo contra su mérito literario o su prestigio, sino también incluso contra su propia persona, bajo la acusación de "best-seller de la dictadura". Este movimiento, además, deposita en la literatura cierto gesto romántico que, antes que ingenuo, provocador o pueril, preferiríamos acercar a la noción programática de "autofundación en lo simbólico", en el sentido que Dany-Robert Dufour entiende los procesos de definición autorreferencial típicos de la democracia moderna (152), y que Jorge Asís ha demostrado llevar adelante a través de toda su obra. De ahí que, por su capacidad para interrogar y polemizar con "los límites del canon", lo que Jorge Asís despliega a partir de las trampas voluntarias o azarosas de su propia ambigüedad resuene, más allá de la particularidad de su caso, cada vez que intenta abordarse el estudio de la literatura argentina. 


\section{Obras citadas}

Amarouch, Abdelhamid. "Jorge Asís, un best-seller en plena dictadura militar: triunfo y consecuencias”. Anales de Literatura Hispanoamericana 30 (2001): 249-68.

Asís, Jorge. Canguros (Canguros III). Buenos Aires: Sudamericana, 1983.

- Carne picada (Canguros II). Buenos Aires: Sudamericana, 1981.

_.. Cuaderno del acostado. Buenos Aires: Planeta, 1988.

_.. Del Flore a Montparnasse: el sentido de la vida en el socialismo. Buenos Aires:

Sudamericana, 2000.

__. Don Abdel Zalim: el burlador de Domínico. Buenos Aires: Corregidor, 1972.

__. La ficción política. Buenos Aires: Sudamericana, 1985.

- Flores robadas en los jardines de Quilmes (Canguros I). Buenos Aires: Sudamericana, 1980.

. El kirchnerismo póstumo: el epílogo de la revolución imaginaria. Buenos Aires: Planeta, 2011.

Avellaneda, Andrés. “'Best-seller' y código represivo en la narrativa argentina del ochenta: el caso Asís”. Revista Iberoamericana 125.49 (1983): 983-96.

Ávila Martín, Carmen y Francisco Linares Alés. "Algunas nociones sociocríticas y la dimensión cultural de las palabras”. Sociocriticism 25.1-2 (2010): 93-118.

Bourdieu, Pierre. Campo de poder, campo intelectual: itinerario de un concepto. Buenos Aires: Montressor, 2002.

. El campo político. Trad. Noemí Larrazabal y Emmanuel Capdepont. La Paz: Plural, 2001.

Burgos, Nidia. Jorge Asís: los límites del canon. Buenos Aires: Catálogos, 2001.

Casas de Faunce, María. La novela picaresca latinoamericana. Madrid: Planeta, 1977.

Colonna, Vincent. L'autofiction: essai sur la fictionalisation de soi en littérature. Tesis de Doctorado. Paris: École des Hautes Études en Sciences Sociales, 1989.

De Man, Paul. "Autobiografía como desfiguración”. Trad. Ángel Loureiro. Suplementos Anthropos 29 (1991): 113-17.

Deleuze, Gilles. Crítica y clínica. Trad. Thomas Kauf. Barcelona: Anagrama, 1996.

Dufour, Dany-Robert. El arte de reducir cabezas: sobre la servidumbre del hombre liberado en la era del capitalismo total. Trad. Alcira Bixio. Buenos Aires: Paidós, 2007. 
Eagleton, Terry. Marxismo y crítica literaria. Trad. Laura Vilches. Buenos Aires: Paidós, 2013.

Gregorich, Luis. "Literatura. Una descripción del campo: narrativa, periodismo, ideología. Represión y reconstrucción de una cultura: el caso argentino. Ed. Saúl Sosnowski. Buenos Aires: Eudeba, 1988. 109-24.

Groys, Boris. Volverse público: las transformaciones del arte en el ágora contemporánea. Trad. Paola Cortés Rocca. Buenos Aires: Caja Negra, 2016.

Jameson, Fredric. Los estudios culturales. Trad. Matías Battistón. Buenos Aires: Godot, 2016.

Link, Daniel. Leyenda. Literatura argentina: cuatro cortes. Buenos Aires: Entropía, 2006.

Maristany, José Javier. "Contestación ostentatoria y adhesión: Flores robadas en los jardines de Quilmes". Narraciones peligrosas: resistencia y adhesión en las novelas del Proceso. Buenos Aires: Biblos, 1999. 137-56.

Mavrakis, Nicolás. "La literatura de Jorge Asís". Revista Paco. Web. 27 de julio de 2015.

Palmer, Marcus Sylvan. Narrator transformations in the work of Arab-Argentine writer Jorge Asís. Tesis de Doctorado. University of Iowa, 2014.

Pozuelo Yvancos, José María. Figuraciones del yo en la narrativa: Javier Marías y E. Vila Matas. Valladolid: Cátedra Miguel Delibes y Universidad de Valladolid, 2010.

Raga Rosaleny, Vicente. "Alegoría e ironía: Paul de Man y la ironía posmoderna". Thémata. Revista de Filosofía 39 (2007): 491-97.

Rella, Franco. “La arqueología de lo inmediato”. Entrevista de Mercedes Daguerre y Giulio Lupo. El debate Modernidad/Posmodernidad. Ed. Nicolás Casullo. Buenos Aires: El cielo por asalto, 1993. 239-58.

Ricoeur, Paul. Tiempo y narración. Trad. Agustín Neira. México: Siglo XXI, 1995. 3 vols.

Rodríguez Cascante, Francisco. "El género autobiográfico y la construcción del sujeto autorreferencial". Revista de Filología y Linguística 26.2 (2000): 9-24.

Sarlo, Beatriz. "Política, ideología y figuración literaria". Ficción y politica. La narrativa argentina durante el proceso militar. Buenos Aires: Alianza, 1987. 30-59.

. Tiempo pasado. Cultura de la memoria y giro subjetivo: una discusión. Buenos Aires: Siglo XXI, 2005.

Sloterdijk, Peter. Ira y tiempo: ensayo psicopolitico. Trad. Miguel Ángel Vega Cernuda y Elena Serrano Bertos. Madrid: Siruela, 2010. 
Steyerl, Hito. Los condenados de la pantalla. Trad. Marcelo Expósito. Buenos Aires: Caja Negra, 2014.

Streeck, Wolfgang. Comprando tiempo: la crisis pospuesta del capitalismo democrático. Trad. Gabriel Barpal. Buenos Aires: Katz, 2016.

Viñas, David. Literatura argentina y política: de los jacobinos porteños a la bohemia anarquista. Vol. 1. Buenos Aires: Santiago Arcos, 2005.

Žižek, Slavoj. El acoso de las fantasías. Trad. Clea Braunstein Saal. Buenos Aires: Siglo XXI, 1999.

__. El sublime objeto de la ideología. Trad. Isabel Vericat Núñez. Buenos Aires: Siglo XXI, 1992. 